Article

\title{
Ice Storage Air-Conditioning System Simulation with Dynamic Electricity Pricing: A Demand Response Study
}

\author{
Chi-Chun Lo ${ }^{1,2,+}$, Shang-Ho Tsai ${ }^{1,+}$ and Bor-Shyh Lin ${ }^{3, *}$ \\ 1 Institute of Electrical and Control Engineering, National Chiao Tung University, Hsinchu 30010, Taiwan; \\ chichun@cgmh.org.tw (C.-C.L.); f0910051931@gmail.com (S.-H.T.) \\ 2 Department of Engineering and Maintenance, Chang Gung Memorial Hospital, Kaosiung 83301, Taiwan \\ 3 Institute of Imaging and Biomedical Photonics, National Chiao Tung University, Tainan 71150, Taiwan \\ * Correspondence: gpapersubmmit@gmail.com; Tel.: +886-6-303-2121 (ext. 57835) \\ + These authors contributed equally to this work.
}

Academic Editor: Susan Krumdieck

Received: 13 November 2015; Accepted: 28 January 2016; Published: 18 February 2016

\begin{abstract}
This paper presents an optimal dispatch model of an ice storage air-conditioning system for participants to quickly and accurately perform energy saving and demand response, and to avoid the over contact with electricity price peak. The schedule planning for an ice storage air-conditioning system of demand response is mainly to transfer energy consumption from the peak load to the partial-peak or off-peak load. Least Squares Regression (LSR) is used to obtain the polynomial function for the cooling capacity and the cost of power consumption with a real ice storage air-conditioning system. Based on the dynamic electricity pricing, the requirements of cooling loads, and all technical constraints, the dispatch model of the ice-storage air-conditioning system is formulated to minimize the operation cost. The Improved Ripple Bee Swarm Optimization (IRBSO) algorithm is proposed to solve the dispatch model of the ice storage air-conditioning system in a daily schedule on summer. Simulation results indicate that reasonable solutions provide a practical and flexible framework allowing the demand response of ice storage air-conditioning systems to demonstrate the optimization of its energy savings and operational efficiency and offering greater energy efficiency.
\end{abstract}

Keywords: ice storage system; air-conditioning system; dynamic electricity price; demand response; bee swarm optimization

\section{Introduction}

In recent years, due to rapid industrial development, the electricity demand growth has been substantial. In the summer, the peak load continues to rise year by year, but international oil costs and production lack stability. Therefore, there is an urgent need to seek and develop alternative sources of energy, as well as to carry out comprehensive reviews of the efficiency of using these energy sources. Thus, improving the efficiency of the chiller units to reduce electricity costs is very important. Currently, public buildings, such as large hospitals, office buildings and shopping malls, use central air-conditioning systems. In the current design of large-scale central air-conditioning systems, the main structure includes fans, ice water pumps, chiller units, cooling water pumps and cooling fans. By using the hot and cold exchange system, the indoor temperature heat load is transferred to the outdoors and the cooling load is about $40 \%$ of the total power load. The system peak loads may not be met by the air-conditioning system, so the ice storage technology has begun to be used for reducing 
energy consumption. An ice storage system can reduce the off-peak demand load so the power charges are at the off-peak rate. The central ice storage air-conditioning system [1,2], which integrates chillers and an ice storage tank, has been effectively applied to the management of demand response.

The ice storage system runs the refrigerating compressor with off-peak loads during the night. The water is frozen to store plenty of latent heat by phase change, and then it is discharged to reduce the load profile of the air conditioning on peak load or partial-peak load during the day [3].

The economical and operational benefits offered by the chiller dispatch under time-of-use (TOU) [4] in Taiwan. This not only reduces the on-peak load for demand response, but also lowers the electricity price as the preferential rates are shifted from the peak load profile to off-peak periods. The ice storage tank shifts the peak load to off-peak hours in order to reduce the problem of overloads during peak hours, thereby improving the efficiency of off-peak electricity use and balancing electricity consumption. Therefore, the demand response strategies in an ice storage air-conditioning system are very important for saving energy [5]. The ice storage air-conditioning system is a combination of different chiller units and an ice storage tank, each with their own characteristic curves and different operating limitations. In related studies, the cubic equation was used to construct the characteristic curve to achieve higher accuracy; the accuracy of the efficiency curve of each chiller unit and the ice storage tank was improved, but the difficulty of the problem increased.

The problem is scheduling of the ice storage air-conditioning system for the industry, service industry, and large commercial office centers. Sun and Reddy [6] used a Taylor-Series expansion to solve the economic dispatch of chiller plants problem in order to find the optimal cooling load share for chiller units with different efficiencies. In reference [7] a particle swarm algorithm was used to facilitate optimization of ice-storage air-conditioning systems and to develop optimal operating strategies. In [3] the use of ice thermal energy storage to reduce and shift the electricity consumption of air-conditioning systems from on-peak hours to off-peak hours was proposed. In [8] ice storage systems were used to shift the peak cooling demand to off-peak periods in office buildings and several other studies have discussed the optimal design and control of cooling systems with ice storage [9-11].

A high-dimensional ice storage air-conditioning system presents a complex problem. In recent years, numerous experts and scholars have adopted the labor division and cooperation procedures of biological communities to develop many heuristic algorithms. Several studies have been carried out on the effectiveness of energy storage systems and the related literature includes the combination of sequential quadratic programming (SQP) [12,13], evolutionary programming (EP) [14], or the particle swarm algorithm (PSO) [15,16]. Also, optimization methods for initial solutions have often been adopted $[17,18]$. In particular, the particle swarm algorithm containing time-varying acceleration coefficients $[19,20]$ was proposed for application in a variety of optimization problems. By using time-varying weight factors, the search space and accuracy of the algorithm have been improved. These hybrid and weight factor adjustment optimization methods are worth further study and discussion.

The enhanced bee swarm optimization algorithm (EBSO) [21] is a kind of optimization technique based on collective intelligence that originates from the foraging behavior of bees. Bee swarms communicate and collaborate with each other through pheromones to exhibit intelligent behavior. This behavior has been used in the development of several related algorithms [22] and applied to actual optimization problems. In this paper, the improved ripple bee swarm optimization (IRBSO) uses nonlinear ripple weight factors to improve the behavior pattern of each bee swarm and increase its search efficiency and accuracy in high dimensions. The cognitive and social parameter factors use nonlinear ripple weight to improve the search ability. In this paper, the IRBSO is proposed to solve the system's dynamic electricity price for demand response requires. In our results show that the proposed method is feasible, robust, and more effective than many previously developed algorithms.

\section{System Structure}

The main structure of a large-scale central ice storage air-conditioning system includes fans, ice water pumps, chillers, an ice storage tank, ice storage pump, cooling water pumps and cooling 
fans, as shown in Figure 1. To meet the cooling load and provide large buildings with a stable supply, multiple chiller units are operated in parallel and connected to a common supply system. By using the hot and cold exchange system, the indoor temperature heat load is transferred to the outdoors. This architecture can effectively make the chiller and ice storage operations more flexible and reliable, as well as provide a standby capacity, while requiring lower unit maintenance costs. The ice storage air-conditioning system of demand response works by operating the ice storage tank to take advantage of the off-peak electricity price.

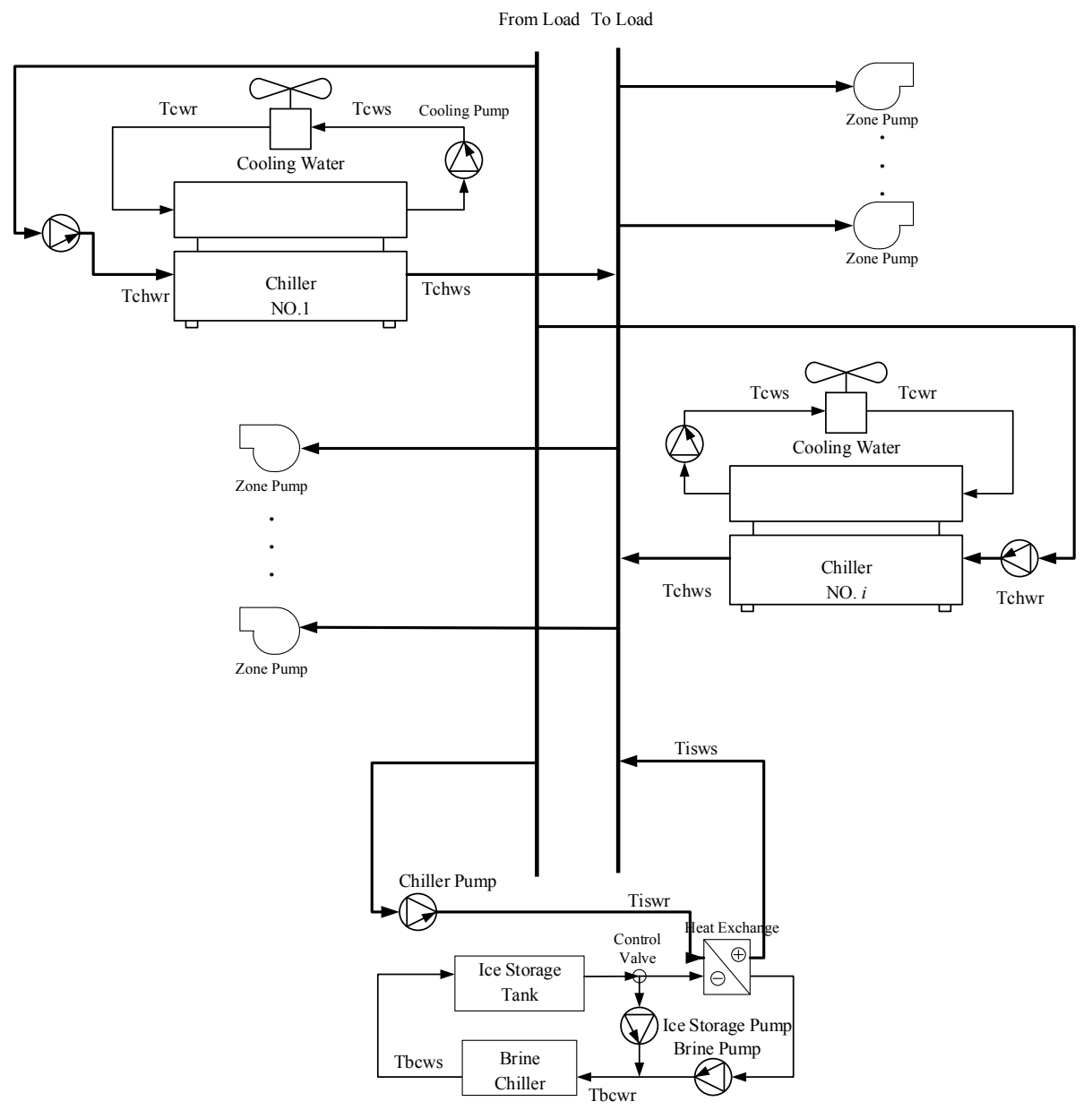

Figure 1. Ice storage air-conditioning system.

The cold energy is stored in the form of sensible heat, and the ice is melted into water to release cold energy in order to provide the required cooling load. In this way, air-conditioning demands are met, electricity use during peak hours in the daytime is reduced, the stored ice is released to transfer the peak electricity demands and power costs are reduced. This paper is to derive the best single-day schedule planning for ice storage air-conditioning systems. The mathematical formulas of the chillers and ice storage tank are introduced as follows:

\subsection{Chiller Capacity Cooling Load}

The cooling load capacity is calculated based on the return water temperature and supply water temperature of the chillers, as well as the flow rate of the chilled water. The calculations of the cooling load capacity for the chillers are expressed in Equations (1) and (2):

$$
Q_{\text {chiller }, i}=\left(L P M_{\text {chiller }, i} \times\left(\Delta T_{\text {chw }, i}\right) \times \rho_{w} \times C_{p w}\right) \times 60_{\text {min }}
$$




$$
\Delta T_{\text {chw }, i}=T_{\text {chwrt }, i}-T_{\text {chwst }, i}
$$

$\Delta T_{c h w, i}:$ temperature difference of chilled water $\left({ }^{\circ} \mathrm{C}\right)$

$T_{\text {chwor }, i}:$ the return temperature of chilled water $\left({ }^{\circ} \mathrm{C}\right)$

$T_{\text {chws }, i}:$ the supply temperature of chilled water $\left({ }^{\circ} \mathrm{C}\right)$

$L P M_{\text {chiller }, i}:$ the flow rate of chilled water $(\mathrm{L} / \mathrm{min})$

$\rho_{w}$ : the density of chilled water $\left(1 \mathrm{~kg} / \mathrm{m}^{3}\right)$

$C_{p w}$ : the specific heat of chilled water $(4.186 \mathrm{~kJ} / \mathrm{kg} \cdot \mathrm{K})$

$Q_{\text {chiller }, i}:$ the cooling load of the $i$ th chiller $(\mathrm{kJ} / \mathrm{h})$.

The power consumption of chillers is a convex function of the cooling load capacity and the each chiller represents the operational control in Equations (3) and (4):

$$
\begin{gathered}
Q_{\text {chiller }, i, \text { min }} \leqslant Q_{\text {chiller }, i} \leqslant Q_{\text {chiller }, i, \max } \\
P_{\text {chiller }, i}\left(Q_{\text {chiller }, i}\right)=a_{i}+b_{i} Q_{\text {chiller }, i}+c_{i} Q_{\text {chiller }, i}^{2}+d_{i} Q_{\text {chiller }, i}^{3}
\end{gathered}
$$

where $P_{\text {chiller, } i}$ is the power consumption $(\mathrm{kW})$ of chiller $i$; and $a_{i}, b_{i}, c_{i}$ and $d_{i}$ are the regression coefficients of the operation curve of the $i$ th chiller.

\subsection{Ice Storage Cooling System}

The ice storage tank is stored in the form of sensible heat, and the ice is melted into water to release cold energy in order to provide the required cooling load. The ice storage operation during off-peaks of electricity mainly involves freezing water into ice in order to store the cooling capability; the cooling load capability of the melting ice is calculated using the water temperature differences and the water flow valve. The cooling load capacity of an ice storage tank is calculated based on the return water temperature, supply water temperature and the flow rate of the chilled water. The calculation of the cooling load capacity is represented in Equations (5) and (6):

$$
\begin{gathered}
Q_{i c e}=\Delta T_{i s w} \times L P M \times C_{p w} \times 60_{\text {min }} \\
\Delta T_{i s w}=T_{i s w r}-T_{i s w s}
\end{gathered}
$$

$\Delta T_{i s w}$ : the temperature difference of ice storage water $\left({ }^{\circ} \mathrm{C}\right)$

$T_{\text {iswr }}$ : the return temperature of ice storage water $\left({ }^{\circ} \mathrm{C}\right)$

$T_{i s w s}$ : the supply temperature of ice storage water $\left({ }^{\circ} \mathrm{C}\right)$

LPM: the flow rate of ice storage water $(\mathrm{L} / \mathrm{min})$

$Q_{i c e}$ : cooling load capacity of ice storage tank $(\mathrm{kJ} / \mathrm{h})$.

The operation modes of the ice storage tank can be divided into a "charge process" and a "discharge process". The ice storage operation in the charging process mainly involves freezing water into ice in order to store the cooling capability, while the ice melting in the discharging process supplies the cooling capability. The ice storage power consumption in the charging process is briefly formulated in Equation (7) and the discharging process in Equation (8):

$$
\begin{gathered}
P_{i c e, c p}=a_{c p}+b_{c p} Q_{i c e, c p}+c_{c p} Q_{i c e, c p}^{2}+d_{c p} Q_{i c e, c p}^{3} \\
P_{i c e, d p}=a_{d p}+b_{d p} Q_{i c e, d p}+c_{d p} Q_{i c e, d p}^{2}+d_{d p} Q_{i c e, d p}^{3}
\end{gathered}
$$

where $a_{c p}, b_{c p}, c_{c p}$ and $d_{c p}$ are the regression coefficients of $Q_{i c e, c p}$ and $P_{i c e, c p}$ is the ice storage charge process power $(\mathrm{kW})$. The cooling load capacity of the ice melting is calculated based on the amount of melting ice, where $a_{d p}, b_{d p}, c_{d p}$ and $d_{d p}$ are the regression coefficients of $Q_{i c e, d p}$ and $P_{i c e, d p}$ is the ice storage pump power $(\mathrm{kW})$. 


\subsection{Ice Storage Air-Conditioning System}

The ice storage air-conditioning system's dynamic electricity price for demand response requires minimizing the total operating cost. This paper also considers the connection with a utility company regarding the TOU rate [4]. The total operating cost includes the charging and discharging process of the power from an ice storage tank, which is formulated as Equation (9):

$$
\begin{array}{r}
\text { Min Cost }=\sum_{t=1}^{h}\left(\left(\sum_{i=1}^{j} P_{i}^{t}\left(Q_{\text {chiller }, i}^{t}\right) U_{i}^{t}+S U_{i}^{t}+S D_{i}^{t}\right) \times \text { price }^{t}\right) \\
+\sum_{t=1}^{k_{1}} P_{i c e, c p}^{t}\left(Q_{i c e, c p}^{t}\right) \times \text { price }_{i c e}+\sum_{t=k_{1}+1}^{k_{2}} P_{i c e, d p}^{t}\left(Q_{i c e, d p}^{t}\right) \times \text { price }^{t}
\end{array}
$$

where $h$ is the scheduling hour; $j$ is the total number of chiller units; $U_{i}^{t}$ is the $i$ th chiller's operation status (on/off) at hour $t ; S U$ and $S D$ are the start-on and shut-off power of the chiller units, respectively; price $^{t}$ and price $_{i c e}$ are the dynamic electricity price at hour $t$ and the favorable price for ice storage. The ice storage charge process time is from $t=1$ to $k_{1}=10$ (22:00 p.m. to 07:00 a.m.) have favorable price and discharge processing times is from $t=11$ to $k_{2}=24$ (8:00 a.m. to 21:00 p.m.) used summer power prices. The cooling load of the system can be used according to Equation (10):

$$
\begin{gathered}
C L^{t}=\sum_{t=1}^{h} \sum_{i=1}^{j} Q_{\text {chiller }, i}^{t} U_{i}^{t}+\sum_{t=k_{1}+1}^{k_{2}} Q_{i c e, d p}^{t} \times\left(1-l_{\text {loss }}\right) \\
\text { hour }_{i}^{t}>0 \text { if } U_{i}^{t}=1 \text { than }\left[\text { hour }_{i}^{t-1}-T_{i}^{o n}\right] \times\left[U_{i}^{t-1}-U_{i}^{t}\right] \geqslant 0 \\
\text { hour }_{i}^{t}<0 \text { if } U_{i}^{t}=0 \text { than }\left[- \text { hour }_{i}^{t-1}-T_{i}^{o f f}\right] \times\left[U_{i}^{t}-U_{i}^{t-1}\right] \geqslant 0 \\
\sum_{t=1}^{k_{1}} Q_{i c e, c p}^{t}-\sum_{t=k_{1}+1}^{k_{2}} Q_{i c e, d p}^{t} \times\left(1-l_{\text {loss }}\right)=0
\end{gathered}
$$

where $C L^{t}$ is the system total cooling load at hour $t$; hour ${ }_{i}^{t}$ is the time duration for which unit $i$ has been on or off at time $t$, The chiller unit operation minimum on-time, $T_{i, o n}$, and minimum off-time, $T_{i, o f f}$ constraints are shown in Equations (11) and (12). The $l_{\text {loss }}$ is transmission loss for the ice storage system and $l_{\text {loss }}$ is set to 0.05 . The ice storage tank for the charge process and discharge process for a day can be used according to Equation (13).

\section{Proposed Methodology}

This study proposes an IRBSO in order to achieve the optimal demand response of an ice storage air-conditioning system. The objective is to minimize cost in a daily schedule while satisfying all constraints including cooling loading. The bee swarm algorithm significantly changes the operation mode of bee swarms, which can be divided into forager bees, onlooker bees and scout bees. To further strengthen the global search capability, each bee type uses a different approach. The input data include system total cooling load, dynamic electricity price, operation status of each chiller and cooling load, temperature of chilled water, ice storage charge and discharge processes and the temperature of the ice storage water. The IRBSO parameters include the forager bees, onlooker bees and scout bees, with the total population of bees as $X$, the number of as iter, the nonlinear ripple weight factor as $H$ and the interference factor as $p r$.

Let $B_{x}^{t}=\left\{Q_{\text {chiller, } \mathrm{i}}^{\mathrm{t}}, U_{\mathrm{i}}^{\mathrm{t}}, Q_{\mathrm{ice}, \mathrm{cp}}^{\mathrm{t}}, Q_{i c e, d p}^{t}\right\}$ be an individual, $x=1,2, \ldots, X$ and $X$ is set to 100 in this paper. The population sizes in the IRBSO algorithm are forager bees $40 \%$, onlooker bees $40 \%$ and scout bees $20 \%$. All individuals are set between the lower and upper limits with a uniform distribution, as shown in Equation (14):

$$
B_{x}^{t}=B_{x, \min }^{t}+\text { rand } \times\left(B_{x, \max }^{t}-B_{x, \min }^{t}\right)
$$


where rand is a random variable between 0 and 1 . The fitness score of each $B_{k}^{t}$ is obtained by calculating the objective function.

\subsection{Forager Bees}

The messages of the releaser pheromones and primer pheromones spread in the message exchange area are retrieved by experienced forager bees. The forager bees remember the best location in their own searches, Pbest $t_{x_{1}}^{t}$, and $x_{1}$ is the number of forager bees. This method can effectively strengthen the search range and accuracy, resulting in a higher probability of finding the global optimal solution. The forager bees follow the location of the current optimal solution to search Gbest ${ }^{t}$, as shown in Equation (15):

$$
B_{x_{1}, \text { iter }+1}^{t}=B_{x_{1}, \text { iter }}^{t}+\left(\begin{array}{c}
w_{b} \times r_{b} \times\left(\text { Pbest }_{x_{1}}^{t}-B_{x_{1}, \text { iter }}^{t}\right)+ \\
w_{g} \times r_{g} \times\left(\text { Gbest }^{t}-B_{x_{1}, \text { iter }}^{t}\right)
\end{array}\right)
$$

where $r_{b}$ and $r_{g}$ are two random numbers between 0 and 1 . Some bees flying over some parts of the search space may acquire profitable information from other bee swarms. The bees need to avoid premature convergence and to enlarge the search area to cover places that might have been neglected. The $w_{b}$ and $w_{g}$ determine the importance of the social and cognitive information for each iteration. In this study, $w_{b, \max } w_{b, \min }, w_{g, \max }, w_{g, \min }$ and itermax are set to $1.5,0.8,0.8,1.5$ and 200 , respectively.

In this study, we used the nonlinear sine function and temporal variation as givens in Equations (16) and (17). Based on the resonance of weight factors $w_{b r f}$ and $w_{g r f}$, staggered search results can be achieved in which the nonlinear ripple weight factor is more effective at making the algorithm search better both locally and globally:

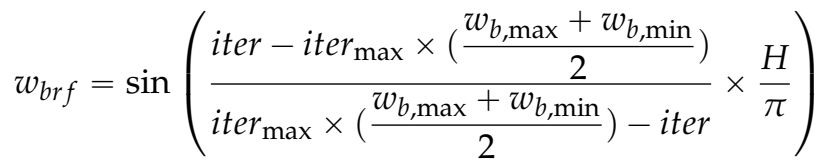

$$
\begin{aligned}
& w_{g r f}=-w_{b r f}
\end{aligned}
$$

where $H$ is set to $0.05,0.1$ and 1 ; the non-linear ripple weight factors can be derived from the $w_{b r f}$ and $w_{\text {grf }}$ ripple resonance curves placed into $w_{b}$ and $w_{g}$, as in Equations (18) and (19), Figures 2 and 3 show the behavior of $w_{b}$ and $w_{g}$ with different values of $H$ :

$$
\begin{aligned}
& w_{b}=w_{b, \min }+\frac{w_{b, \max }-w_{b, \min }}{\text { iter }_{\max }} \times \text { iter }+w_{b r f} \\
& w_{g}=w_{g, \min }+\frac{w_{g, \max }-w_{g, \min }}{\text { iter }_{\max }} \times i t e r+w_{g r f}
\end{aligned}
$$

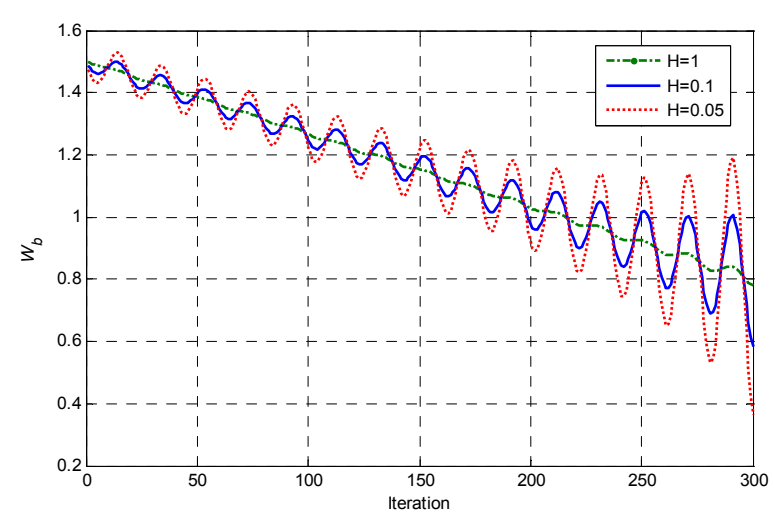

Figure 2. $H$ of $w_{b}$ vs. different iterations. 


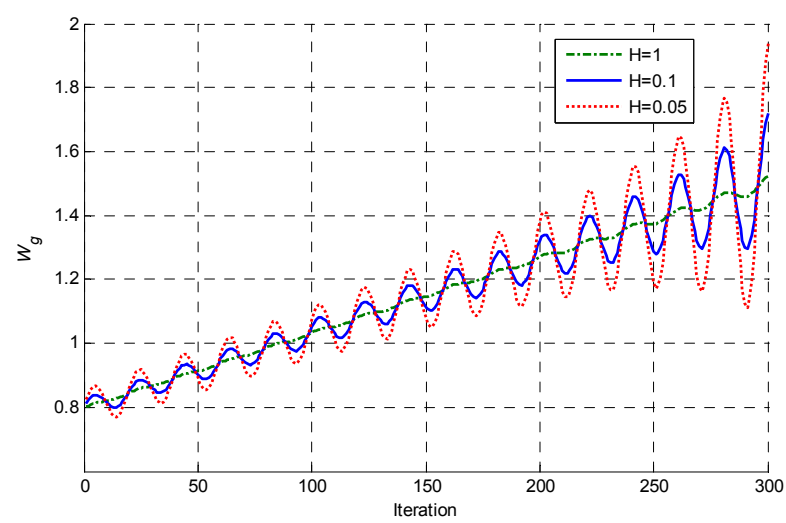

Figure 3. $H$ of $w_{g} v s$. different iterations.

\subsection{Onlooker Bees}

The onlooker bees in the improved bee swarm algorithm follow the experienced forager bees to obtain nectar information. Equation (20) is used for judging whether or not to follow the forager bees for foraging. The onlooker bees use the probabilistic selection method, as shown in Equation (21), to follow the experienced forager bees to gather nectar. In the working mode of the onlooker bees, the interference factor is also included in order to enlarge the search area:

$$
\begin{gathered}
\operatorname{prob}(e)=\frac{1 / \phi\left(B_{x_{1}, \text { iter }}^{t}\right)}{\sum 1 /\left(\phi\left(B_{x_{1}, \text { iter }}^{t}\right)\right)} \\
B_{x_{2}, \text { iter }+1}^{t}=B_{x_{2}, \text { iter }}^{t}+w_{g} \times r \times\left(B_{\text {prob }(e)}^{t}-B_{x_{2}, \text { iter }}^{t}\right)
\end{gathered}
$$

where $\operatorname{prob}(e)$ is the fitness value of the source food; $B_{\operatorname{prob}(e)}^{t}$ is the best source; $x_{2}$ is the number of onlooker bees; and $r$ is a random number between 0 and 1 .

\subsection{Scout Bees}

In the bee swarm algorithm, the model of the scout bees is no longer a baseless random search. In [20], the working model of the scout bees is modified to the average value of the global optimum solution and all swarm locations, as in Equations (22) and (23):

$$
\begin{aligned}
B_{x_{3}, i t e r+1}^{t} & =B_{x_{3}, \text { iter }}^{t}+r \times\left(\text { Gbest }^{t}-l \cdot M_{\text {iter }}\right) \\
l & =\operatorname{round}(1+\operatorname{rand}(0,1))
\end{aligned}
$$

where $x_{3}$ is the number of scout bees; and $M$ is the average of all variable solutions in the iteration.

\subsection{Self-Adaptation Repulsion Factor of Bee Swarm}

To further strengthen the global search capability, the experienced forager bees use different approaches. This procedure causes them to fly over some parts of the search space and may include profitable information from the bee swarm. The increasing diversity of the bee swarm is incorporated in order to avoid premature convergence. To enlarge a search area that might have been neglected, a relevant study suggests the concept of the interference factor, sign. When the randomly generated $\operatorname{rand}(0,1)$ is larger than the predefined $p r$, a reverse search, as given in Equation (24), takes place and $p r$ is initially set to 0.8 :

$$
\operatorname{sign}= \begin{cases}1, & \text { if } \operatorname{rand}(0,1) \leqslant p r \\ -1, & \text { else }\end{cases}
$$


We modified the interference factor, sign, to the self-adaptation repulsion factor, sign, with an initial setting of $p r=0.7$ and the random variable $\operatorname{rand}(0,1)$ for the total number of bee swarms. The sign values used by the bee swarms were recorded, and the $p r$ value based on self-adaptation repulsion was adjusted based on the fitness value for iteration, as in Figure 4.

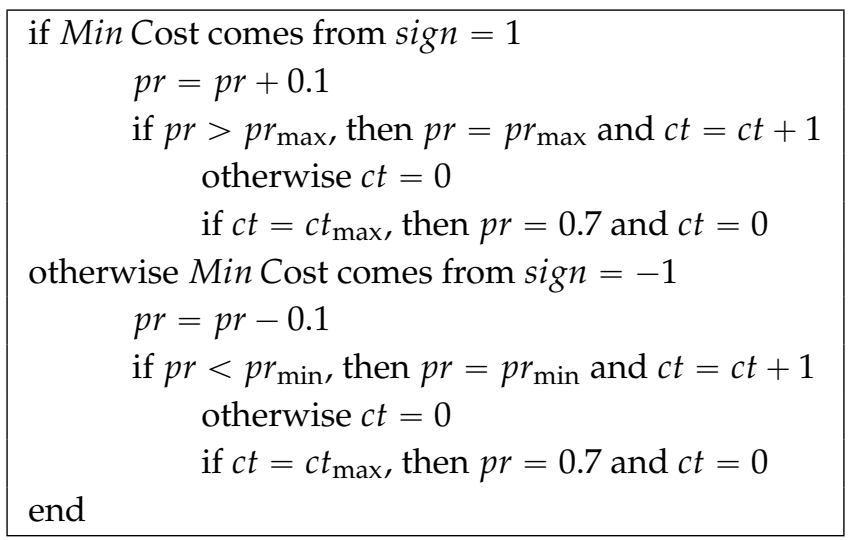

In this paper, $p r_{\max }=0.9$ and $p r_{\min }=0.1$ to prevent $p r$ from becoming extreme, and $c t_{\max }=5$. The updating velocities used in this study improved the diversity of the solutions. This behavior is referred to as the self-adaptation repulsion factor.

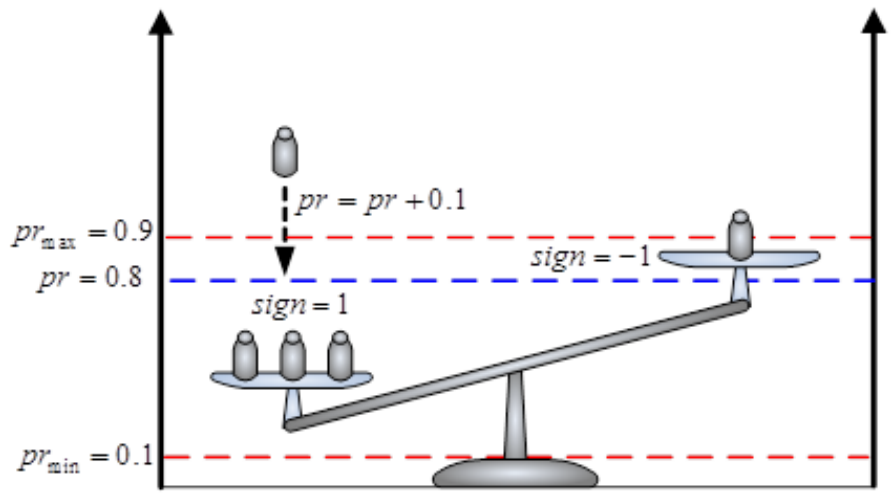

Figure 4. Probability variation of $p r$.

The effect of the repulsion factor for the bee swarm can be expressed as Equations (25) to (27):

$$
\begin{gathered}
B_{x_{1}, \text { iter }+1}^{t}=B_{x_{1}, \text { iter }}^{t}+\operatorname{sign} \times\left(\begin{array}{c}
w_{b} \times r_{b} \times\left(\text { Pbest }_{x_{1}}^{t}-B_{x_{1}, i t e r}^{t}\right)+ \\
w_{g} \times r_{g} \times\left(G b e s t^{t}-B_{x_{1}, i t e r}^{t}\right)
\end{array}\right) \\
B_{x_{2}, i t e r+1}^{t}=B_{x_{2}, i t e r}^{t}+\operatorname{sign} \times w_{g} \times r \times\left(B_{p r o b(e)}^{t}-B_{x_{2}, i t e r}^{t}\right) \\
B_{x_{3}, i t e r+1}^{t}=B_{x_{3}, i t e r}^{t}+\operatorname{sign} \times r \times\left(\text { Gbest }^{t}-l \cdot M_{i t e r}\right)
\end{gathered}
$$

\section{Simulation Results}

In this study we investigated the actual practice in the operation planning of the chiller units and ice storage tank for a hospital. IRBSO, TVAC-PSO and PSO were used to calculate the optimal single-day cooling loads of the dynamic electricity price in summer, along with the derived switch status and which include six chillers and one ice storage tank. The TOU rates for the chillers and ice storage tank was calculated based on the summer date listed in Table 1. 
Table 1. The TOU [4] rate for a summer day.

\begin{tabular}{cclcc}
\hline \multirow{2}{*}{ Hours } & $\begin{array}{c}\text { Load } \\
\text { Classification }\end{array}$ & \multicolumn{2}{c}{ Ice Storage Tank } & Chiller Prices \\
\cline { 3 - 4 } & & Process & Prices (NT\$) & \\
\hline 22:00 & Off-Peak & Charging & 0.942 & 1.57 \\
23:00 & Off-Peak & Charging & 0.942 & 1.57 \\
24:00 & Off-Peak & Charging & 0.942 & 1.57 \\
01:00 & Off-Peak & Charging & 0.942 & 1.57 \\
02:00 & Off-Peak & Charging & 0.942 & 1.57 \\
03:00 & Off-Peak & Charging & 0.942 & 1.57 \\
04:00 & Off-Peak & Charging & 0.942 & 1.57 \\
05:00 & Off-Peak & Charging & 0.942 & 1.57 \\
06:00 & Off-Peak & Charging & 0.942 & 1.57 \\
07:00 & Off-Peak & Charging & 0.942 & 1.57 \\
08:00 & Partial-Peak & Discharging & 3.13 & 3.13 \\
09:00 & Partial-Peak & Discharging & 3.13 & 3.13 \\
10:00 & Peak & Discharging & 4.73 & 4.73 \\
11:00 & Peak & Discharging & 4.73 & 4.73 \\
12:00 & Partial-Peak & Discharging & 3.13 & 3.13 \\
13:00 & Peak & Discharging & 4.73 & 4.73 \\
14:00 & Peak & Discharging & 4.73 & 4.73 \\
15:00 & Peak & Discharging & 4.73 & 4.73 \\
16:00 & Peak & Discharging & 4.73 & 4.73 \\
17:00 & Partial-Peak & Discharging & 3.13 & 3.13 \\
18:00 & Partial-Peak & Discharging & 3.13 & 3.13 \\
19:00 & Partial-Peak & Discharging & 3.13 & 3.13 \\
20:00 & Partial-Peak & Discharging & 3.13 & 3.13 \\
21:00 & Partial-Peak & Discharging & 3.13 & 3.13 \\
\hline & & & & \\
\hline
\end{tabular}

All the simulations were carried out with MATLAB 7.6 on a Core i5, 3.0 GHz personal computer with 8 GB of RAM. The relevant information for each chiller and the ice storage included the hourly recorded operating coefficients from March to December in 2013 for the data modeling. The cooling capability for each refrigerating ton (RT) is $12,658.46 \mathrm{~kJ} / \mathrm{h}$ and operating parameters of the 6 chiller units and the ice storage tank of $8000 \mathrm{RT}$. By using the measurement data, the least squares method (LSR) was used to get the input-output (I/O) operation curves of the chillers and the ice storage tank as shown in Tables 2 and 3. Customers operating ice storage central air conditioning system are eligible for a $40 \%$ discount on the energy charge for the system's off-peak kWh consumption in Taiwan.

Table 2. Operational constraints for chillers 1 to 6 .

\begin{tabular}{ccccccc}
\hline Chiller & $P_{\text {chiller }, 1}$ & $P_{\text {chiller }, 2}$ & $P_{\text {chiller }, 3}$ & $P_{\text {chiller }, 4}$ & $P_{\text {chiller }, 5}$ & $P_{\text {chiller }, 6}$ \\
\hline Min on-time & 1 & 1 & 2 & 2 & 3 & 3 \\
Min off-time & 1 & 1 & 2 & 2 & 3 & 3 \\
SU $(\mathrm{kW})$ & 30 & 30 & 40 & 40 & 50 & 50 \\
SD $(\mathrm{kW})$ & 30 & 30 & 40 & 40 & 50 & 50 \\
\hline
\end{tabular}


Table 3. Chillers 1 to 6 and ice storage tank.

\begin{tabular}{ccccccc}
\hline Chiller Unit (kW) & $a$ & $b$ & $c$ & $d$ & $\begin{array}{c}Q_{\text {chiller,min }} \\
\text { (RT) }\end{array}$ & $\begin{array}{c}Q_{\text {chiller,max }} \\
\text { (RT) }\end{array}$ \\
\hline$P_{\text {chiller }, 1}$ & 65.777 & 0.689 & $1.694 \times 10^{7}$ & $5.429 \times 10^{8}$ & 165 & 550 \\
$P_{\text {chiller }, 2}$ & 128.797 & 0.158 & $1.408 \times 10^{3}$ & $-1.142 \times 10^{6}$ & 165 & 550 \\
$P_{\text {chiller }, 3}$ & 81.407 & 0.423 & $6.317 \times 10^{4}$ & $-3.852 \times 10^{7}$ & 300 & 1000 \\
$P_{\text {chiller }, 4}$ & 107.725 & 0.433 & $2.510 \times 10^{4}$ & $-7.207 \times 10^{8}$ & 300 & 1000 \\
$P_{\text {chiller }, 5}$ & 623.209 & -1.602 & $2.821 \times 10^{3}$ & $-1.156 \times 10^{6}$ & 300 & 1000 \\
$P_{\text {chiller, } 6}$ & 101.536 & 0.299 & $8.498 \times 10^{4}$ & $-4.960 \times 10^{7}$ & 300 & 1000 \\
\hline Ice Storage Tank Charge & $a_{c p}$ & $b_{c p}$ & $c_{c p}$ & $d_{c p}$ & $Q_{\text {ice,cp,min }}$ & $Q_{\text {ice,cp,max }}$ \\
Process (kW) & 42.999 & 1.105 & $-1.772 \times 10^{3}$ & $1.252 \times 10^{6}$ & 100 & 700 \\
\hline Ice Storage Tank Discharge & $a_{d p}$ & $b_{d p}$ & $c_{d p}$ & $d_{d p}$ & $Q_{\text {ice,dp,min }}$ & $Q_{\text {ice,dp,max }}$ \\
Process (kW) & -2.256 & 0.071 & $5.485 \times 10^{5}$ & $-4.872 \times 10^{8}$ & 105.26 & 1263.16 \\
\hline
\end{tabular}

\subsection{Dynamic Electricity Price and Ice Storage Tank Strategy for Case Study}

The ice storage tank model included the demand response, the average discharge and the situation without an ice storage tank to determine the dynamic electricity price in the case tests. Table 4 shows the respective simulation results for the objective programming of the case for the total scheduling of a day. That minimized the total cost and dispatch of an ice storage tank in summer. Different models had different results, and all constraints were met for the case study. The results obtained by the IRBSO for this case and other methods, which have been reported in the literature, are summarized in Table 4, which shows the total cost values achieved using the IRBSO algorithm for the demand response, average discharge and no ice storage tank to be better than those of the PSO, TVAC-PSO and BSO methods.

Table 4. The ice storage air conditioning with dynamic electricity price on a summer day (16 July 2013).

\begin{tabular}{ccccc}
\hline \multirow{2}{*}{ Modeling Results } & \multicolumn{4}{c}{ Total Cost (NT\$) } \\
\cline { 2 - 5 } & PSO [17] & TVAC-PSO [21] & BSO [21] & IRBSO \\
\hline Demand Response & 203,641 & 202,615 & 202,754 & $\mathbf{2 0 1 , 1 4 2}$ \\
Average Discharge * & 207,341 & 206,072 & 206,162 & $\mathbf{2 0 4 , 7 4 1}$ \\
No Ice storage Tank & 218,648 & 217,861 & 217,874 & $\mathbf{2 1 7 , 2 9 8}$ \\
\hline
\end{tabular}

* Average Discharge: The cooling load of discharge is identical.

From Figure 5, the ice storage tank of demand response supplies the required cooling load during peak periods and all chillers are appropriately dispatched to achieve minimal cost on a summer day for IRBSO. The improvement of the IRBSO over other algorithms was clear. Figure 6 illustrates the convergence characteristics of PSO, TVAC-PSO, BSO and IRBSO in the demand response scenario, which also showed the capacity of IRBSO to explore a more likely global optimum. The demand response modeling total cost of 201142 (NT\$) for the IRBSO used in case study. The results, showed the capability of IRBSO to explore a more likely global optimum. 


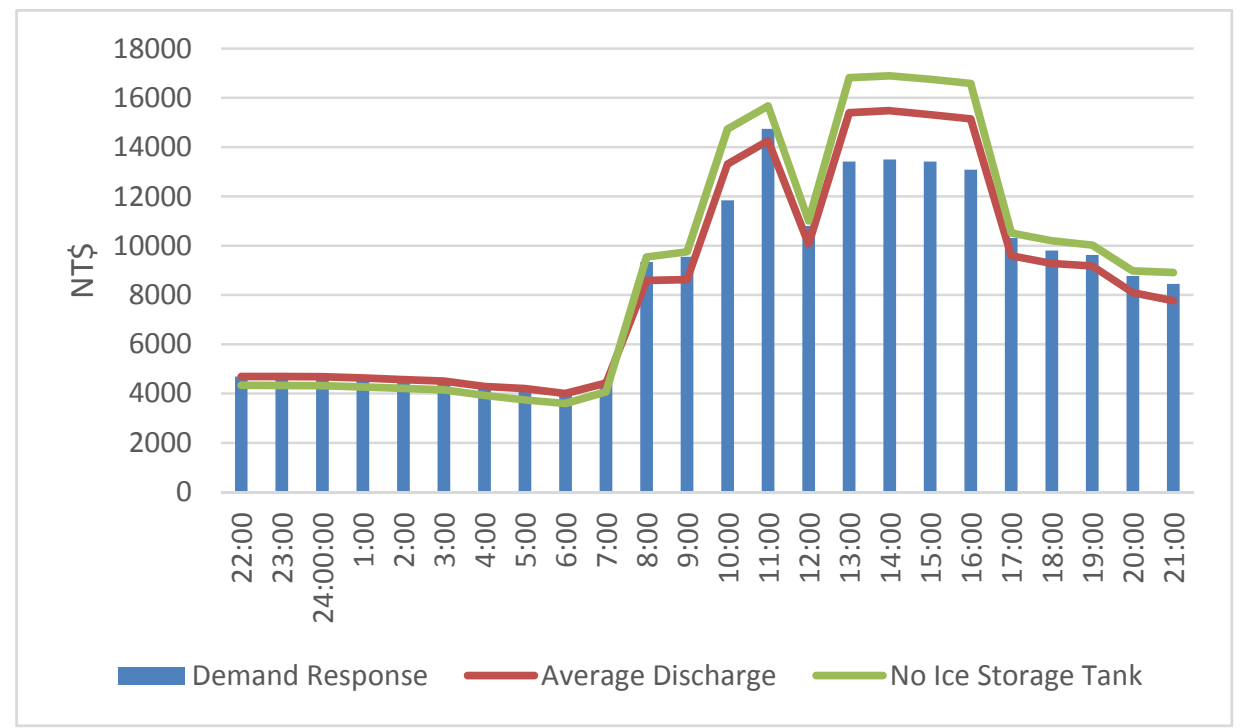

Figure 5. The dynamic electricity price on a summer day (16 July 2013) for IRBSO.

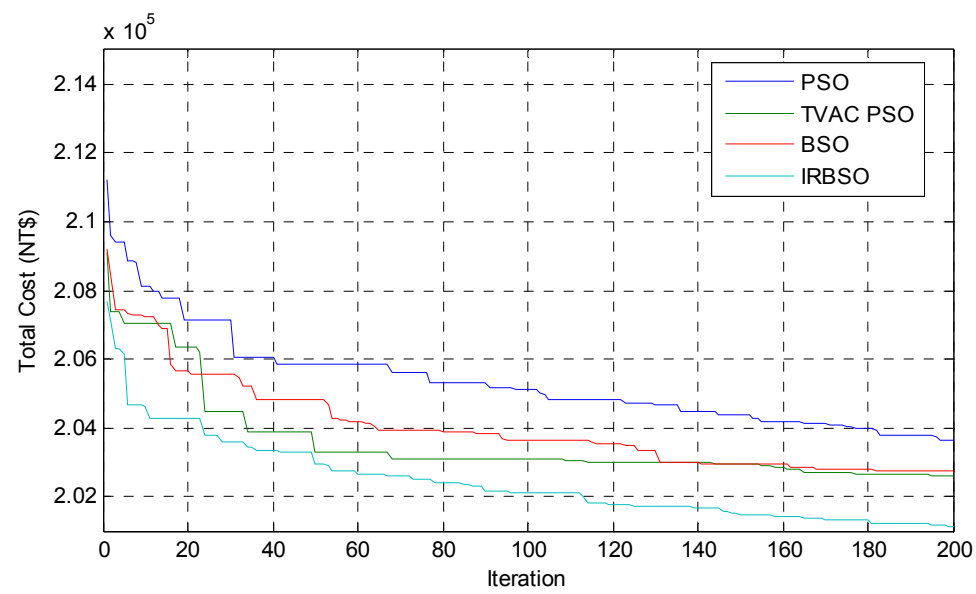

Figure 6. Convergence characteristics of PSO, TVAC-PSO, BSO and IRBSO for demand response scenario.

Table 5 shows the ice storage air conditioning of average discharge and Tables 6 and 7 show the IRBSO at the dynamic electricity price intervals for demand response.

Table 5. The IRBSO for ice storage air conditioning of average discharge.

\begin{tabular}{|c|c|c|c|c|c|c|c|c|}
\hline \multirow{2}{*}{ Hours } & \multirow{2}{*}{$\begin{array}{c}\text { Ice Storage } \\
\text { Tank Cooling } \\
\text { Load (RT) } \\
\text { Discharging }\end{array}$} & \multicolumn{6}{|c|}{ Cooling Load of Chiller (RT) } & \multirow{2}{*}{$\begin{array}{l}\text { Total Cooling } \\
\text { Load (RT) }\end{array}$} \\
\hline & & $\boldsymbol{P}_{\text {chiller }, \mathbf{1}}$ & $\boldsymbol{P}_{\text {chiller }, \mathbf{2}}$ & $\boldsymbol{P}_{\text {chiller }, 3}$ & $\boldsymbol{P}_{\text {chiller }, \mathbf{4}}$ & $\boldsymbol{P}_{\text {chiller }, \mathbf{5}}$ & $\boldsymbol{P}_{\text {chiller }, \mathbf{6}}$ & \\
\hline 22:00 & 0 & 0 & 0 & 1000.00 & 783.00 & 1000.00 & 1000.00 & 3783 \\
\hline 23:00 & 0 & 0 & 0 & 1000.00 & 782.15 & 999.85 & 1000.00 & 3782 \\
\hline 24:00 & 0 & 0 & 0 & 1000.00 & 798.92 & 972.08 & 1000.00 & 3771 \\
\hline 01:00 & 0 & 0 & 0 & 1000.00 & 760.00 & 965.00 & 1000.00 & 3725 \\
\hline 02:00 & 0 & 0 & 0 & 1000.00 & 680.87 & 988.13 & 1000.00 & 3669 \\
\hline 03:00 & 0 & 0 & 0 & 1000.00 & 611.48 & 994.52 & 1000.00 & 3606 \\
\hline 04:00 & 0 & 0 & 0 & 1000.00 & 629.19 & 773.81 & 1000.00 & 3403 \\
\hline 05:00 & 0 & 499.76 & 0 & 440.21 & 921.86 & 1000.00 & 354.17 & 3216 \\
\hline 06:00 & 0 & 0 & 0 & 720.77 & 916.90 & 983.37 & 481.96 & 3103 \\
\hline 07:00 & 0 & 0 & 0 & 1000.00 & 568.55 & 962.45 & 1000.00 & 3531 \\
\hline 08:00 & 475 & 0 & 293.57 & 1000.00 & 955.09 & 1000.00 & 342.34 & 4066 \\
\hline
\end{tabular}


Table 5. Cont.

\begin{tabular}{|c|c|c|c|c|c|c|c|c|}
\hline \multirow{2}{*}{ Hours } & \multirow{2}{*}{$\begin{array}{c}\text { Ice Storage } \\
\text { Tank Cooling } \\
\text { Load (RT) } \\
\text { Discharging }\end{array}$} & \multicolumn{6}{|c|}{ Cooling Load of Chiller (RT) } & \multirow{2}{*}{$\begin{array}{c}\text { Total Cooling } \\
\text { Load (RT) }\end{array}$} \\
\hline & & $\boldsymbol{P}_{\text {chiller }, \mathbf{1}}$ & $\boldsymbol{P}_{\text {chiller }, \mathbf{2}}$ & $\boldsymbol{P}_{\text {chiller }, 3}$ & $\boldsymbol{P}_{\text {chiller } \mathbf{4}}$ & $\boldsymbol{P}_{\text {chiller }, \mathbf{5}}$ & $\boldsymbol{P}_{\text {chiller }, \mathbf{6}}$ & \\
\hline 09:00 & 475 & 0 & 345.57 & 999.38 & 996.32 & 1000.00 & 303.74 & 4120 \\
\hline $10: 00$ & 475 & 0 & 414.74 & 1000.00 & 994.66 & 1000.00 & 321.60 & 4206 \\
\hline $11: 00$ & 475 & 0 & 254.31 & 1000.00 & 752.69 & 1000.00 & 1000.00 & 4482 \\
\hline $12: 00$ & 475 & 267.44 & 460.44 & 1000.00 & 976.62 & 1000.00 & 456.50 & 4636 \\
\hline $13: 00$ & 475 & 480.75 & 376.12 & 1000.00 & 967.31 & 1000.00 & 437.82 & 4737 \\
\hline 14:00 & 475 & 165.00 & 281.12 & 1000.00 & 838.88 & 1000.00 & 1000.00 & 4760 \\
\hline $15: 00$ & 475 & 379.96 & 550.00 & 1000.00 & 968.16 & 1000.00 & 344.88 & 4718 \\
\hline $16: 00$ & 475 & 550.00 & 344.89 & 1000.00 & 983.67 & 1000.00 & 312.43 & 4666 \\
\hline $17: 00$ & 475 & 0 & 225.44 & 1000.00 & 805.56 & 1000.00 & 1000.00 & 4506 \\
\hline 18:00 & 475 & 193.67 & 0 & 1000.00 & 652.33 & 1000.00 & 1000.00 & 4321 \\
\hline 19:00 & 475 & 0 & 450.70 & 1000.00 & 772.13 & 859.60 & 686.58 & 4244 \\
\hline $20: 00$ & 475 & 0 & 0 & 1000.00 & 610.64 & 813.36 & 1000.00 & 3899 \\
\hline 21:00 & 475 & 0 & 0 & 1000.00 & 582.00 & 731.00 & 1000.00 & 3788 \\
\hline Total & 6650 & 2536.59 & 3996.90 & $23,160.36$ & $19,308.99$ & $23,043.15$ & $18,042.01$ & 96,738 \\
\hline
\end{tabular}

Table 6. The IRBSO for ice storage air conditioning of demand response.

\begin{tabular}{|c|c|c|c|c|c|c|c|c|}
\hline \multirow{2}{*}{ Hours } & \multirow{2}{*}{$\begin{array}{c}\text { Cooling Load } \\
\text { of Ice Storage } \\
\text { Tank (RT) } \\
\text { Discharging } \\
\end{array}$} & \multicolumn{6}{|c|}{ Cooling Load of Chiller (RT) } & \multirow{2}{*}{$\begin{array}{l}\text { Total Cooling } \\
\text { Load (RT) }\end{array}$} \\
\hline & & $\boldsymbol{P}_{\text {chiller }, \mathbf{1}}$ & $\boldsymbol{P}_{\text {chiller }, \mathbf{2}}$ & $\boldsymbol{P}_{\text {chiller }, 3}$ & $\boldsymbol{P}_{\text {chiller }, 4}$ & $\boldsymbol{P}_{\text {chiller }, \mathbf{5}}$ & $\boldsymbol{P}_{\text {chiller } \mathbf{6}}$ & \\
\hline $22: 00$ & 0 & 0 & 0 & 1000.00 & 786.36 & 1000.00 & 996.64 & 3783 \\
\hline 23:00 & 0 & 0 & 0 & 1000.00 & 782.00 & 1000.00 & 1000.00 & 3782 \\
\hline 24:00 & 0 & 0 & 0 & 998.26 & 842.82 & 929.93 & 1000.00 & 3771 \\
\hline 01:00 & 0 & 0 & 0 & 1000.00 & 725.00 & 1000.00 & 1000.00 & 3725 \\
\hline 02:00 & 0 & 0 & 0 & 1000.00 & 688.88 & 983.58 & 996.54 & 3669 \\
\hline 03:00 & 0 & 0 & 0 & 983.91 & 622.09 & 1000.00 & 1000.00 & 3606 \\
\hline 04:00 & 0 & 0 & 0 & 1000.00 & 659.58 & 743.42 & 1000.00 & 3403 \\
\hline 05:00 & 0 & 0 & 0 & 1000.00 & 809.21 & 848.97 & 557.82 & 3216 \\
\hline 06:00 & 0 & 0 & 0 & 755.94 & 909.21 & 995.27 & 442.58 & 3103 \\
\hline 07:00 & 0 & 0 & 0 & 978.68 & 669.39 & 882.93 & 1000.00 & 3531 \\
\hline 08:00 & 100 & 0 & 550.00 & 1000.00 & 925.35 & 1000.00 & 490.65 & 4066 \\
\hline 09:00 & 100 & 169.46 & 0 & 1000.00 & 850.54 & 1000.00 & 1000.00 & 4120 \\
\hline 10:00 & 1057.726 & 0 & 325.62 & 482.74 & 968.98 & 1000.00 & 370.93 & 4206 \\
\hline 11:00 & 319.6618 & 0 & 343.19 & 1000.00 & 944.07 & 875.07 & 1000.00 & 4482 \\
\hline 12:00 & 100 & 197.53 & 550.00 & 1000.00 & 788.47 & 1000.00 & 1000.00 & 4636 \\
\hline 13:00 & 1116.346 & 174.34 & 294.55 & 1000.00 & 851.77 & 1000.00 & 300.00 & 4737 \\
\hline 14:00 & 1113.229 & 173.51 & 286.96 & 1000.00 & 874.95 & 1000.00 & 311.34 & 4760 \\
\hline $15: 00$ & 1096.856 & 201.34 & 267.54 & 1000.00 & 843.24 & 1000.00 & 309.03 & 4718 \\
\hline $16: 00$ & 1146.381 & 166.58 & 267.72 & 1000.00 & 780.58 & 1000.00 & 304.74 & 4666 \\
\hline $17: 00$ & 100 & 0 & 406.00 & 1000.00 & 1000.00 & 1000.00 & 1000.00 & 4506 \\
\hline $18: 00$ & 100 & 0 & 306.47 & 1000.00 & 914.53 & 1000.00 & 1000.00 & 4321 \\
\hline $19: 00$ & 100 & 0 & 309.28 & 1000.00 & 834.72 & 1000.00 & 1000.00 & 4244 \\
\hline $20: 00$ & 100 & 0 & 0 & 1000.00 & 799.00 & 1000.00 & 1000.00 & 3899 \\
\hline $21: 00$ & 100 & 0 & 0 & 1000.00 & 730.04 & 957.96 & 1000.00 & 3788 \\
\hline Total & 6650 & 1082.76 & 3907.34 & $23,199.52$ & $19,600.77$ & $23,217.13$ & $19,080.27$ & 96,738 \\
\hline
\end{tabular}

Table 7. Power loads of demand response for IRBSO.

\begin{tabular}{ccccccc}
\hline Hours & Process & $\begin{array}{c}\text { Ice Storage } \\
\mathbf{( k W )}\end{array}$ & $\begin{array}{c}\text { Chiller } \\
\text { Capacity } \mathbf{( k W )}\end{array}$ & $\begin{array}{c}\text { SU \& SD } \\
\mathbf{( k W )}\end{array}$ & $\begin{array}{c}\text { Total } \\
(\mathbf{k W})\end{array}$ & $\begin{array}{c}\text { Total Cost } \\
\mathbf{( N T \$ )}\end{array}$ \\
\hline 22:00 & Charging & 377.66 & 2757.33 & 0 & 3134.99 & 4684.76 \\
23:00 & Charging & 377.66 & 2756.03 & 0 & 3133.69 & 4682.72 \\
$24: 00$ & Charging & 377.66 & 2754.67 & 0 & 3132.33 & 4680.59 \\
$01: 00$ & Charging & 377.66 & 2716.81 & 0 & 3094.47 & 4621.15 \\
$02: 00$ & Charging & 377.66 & 2680.94 & 0 & 3058.59 & 4564.82 \\
\hline
\end{tabular}


Table 7. Cont

\begin{tabular}{ccccccc}
\hline Hours & Process & $\begin{array}{c}\text { Ice Storage } \\
\mathbf{( k W )}\end{array}$ & $\begin{array}{c}\text { Chiller } \\
\text { Capacity } \mathbf{( k W )}\end{array}$ & $\begin{array}{c}\text { SU \& SD } \\
\mathbf{( k W )}\end{array}$ & $\begin{array}{c}\text { Total } \\
\mathbf{( k W )}\end{array}$ & $\begin{array}{c}\text { Total Cost } \\
\mathbf{( N T \$ )}\end{array}$ \\
\hline 03:00 & Charging & 377.66 & 2638.95 & 0 & 3016.60 & 4498.90 \\
04:00 & Charging & 377.66 & 2502.73 & 0 & 2880.39 & 4285.04 \\
05:00 & Charging & 377.66 & 2370.06 & 0 & 2747.71 & 4076.74 \\
06:00 & Charging & 377.66 & 2290.54 & 0 & 2668.20 & 3951.90 \\
07:00 & Charging & 377.66 & 2593.62 & 0 & 2971.28 & 4427.74 \\
08:00 & Discharging & 5.32 & 2948.25 & 30 & 2953.57 & 9338.56 \\
09:00 & Discharging & 5.32 & 2986.76 & 60 & 2992.08 & 9553.02 \\
10:00 & Discharging & 76.31 & 2366.56 & 60 & 2442.87 & 11838.57 \\
11:00 & Discharging & 24.38 & 3093.55 & 0 & 3117.93 & 14747.79 \\
12:00 & Discharging & 5.32 & 3414.46 & 30 & 3419.79 & 10797.83 \\
13:00 & Discharging & 77.32 & 2759.21 & 0 & 2836.54 & 13416.82 \\
14:00 & Discharging & 77.29 & 2777.48 & 0 & 2854.77 & 13503.05 \\
15:00 & Discharging & 77.07 & 2759.79 & 0 & 2836.86 & 13418.34 \\
16:00 & Discharging & 77.56 & 2689.13 & 0 & 2766.68 & 13086.42 \\
17:00 & Discharging & 5.32 & 3258.81 & 30 & 3264.13 & 10310.63 \\
18:00 & Discharging & 5.32 & 3125.70 & 0 & 3131.02 & 9800.10 \\
19:00 & Discharging & 5.32 & 3071.31 & 0 & 3076.63 & 9629.86 \\
20:00 & Discharging & 5.32 & 2767.83 & 30 & 2773.16 & 8773.88 \\
21:00 & Discharging & 5.32 & 2695.15 & 0 & 2700.47 & 8452.48 \\
& Total & 4229.05 & 700.00 & 240 & $71,004.73$ & $201,141.71$ \\
\hline
\end{tabular}

Figure 7 shows the respective approximate thermal energy stored in the ice storage tank during the charging and discharging processes, i.e., the building cooling load. As Figures 7 and 8 show, during off-peak hours for the cooling load of chiller units, the ice-storage tank is in a charging process. During peak-load hours, the discharging process of the ice-storage tank provides the building's required cooling load. As the results show, the ice storage air-conditioning system utilizing IRBSO for the demand response evidenced better planning of the charging and discharging procedures.

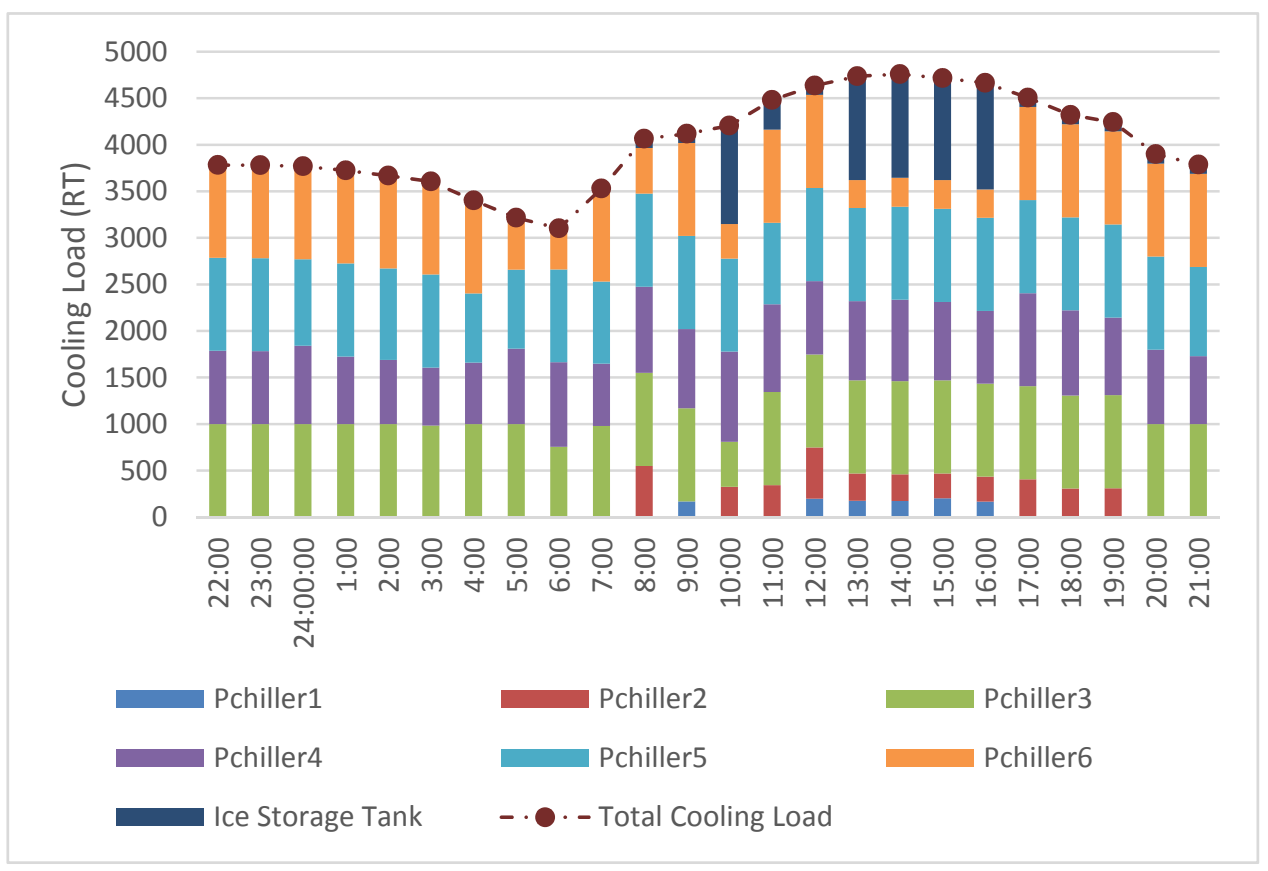

Figure 7. Cooling capability provided by each chiller and the ice storage tank on a summer day (16 July 2013). 


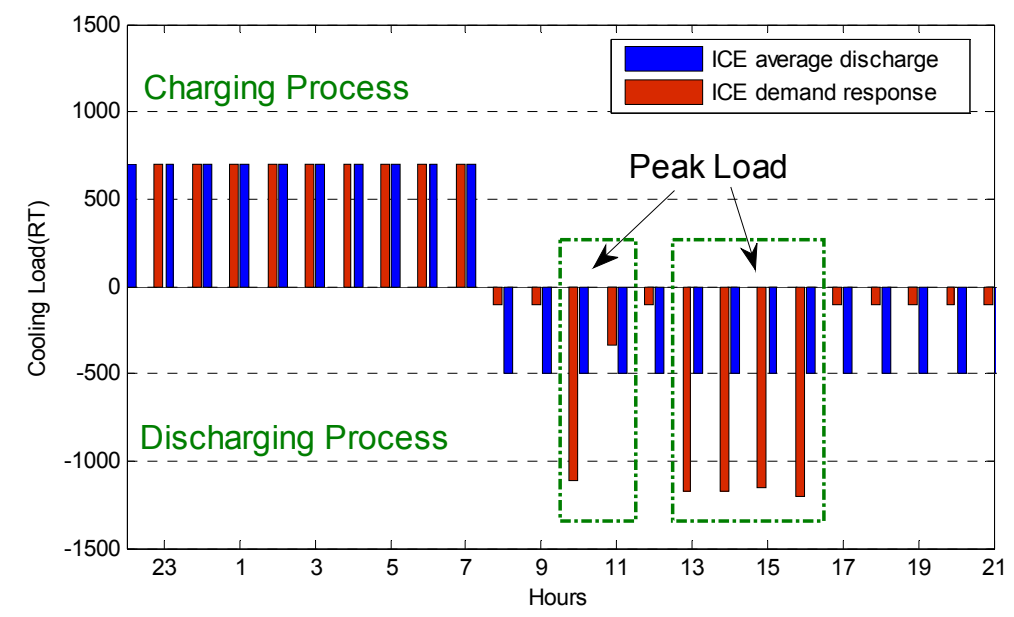

Figure 8. Operating types of ice storage tank in summer.

\subsection{Simulation of Demand Response}

From Table 8, the total power consumption of a day did not clearly change but Table 9 clearly shows the maximum peak-load reduction in the summer, with the drop in power cost dependent on the dynamic electricity price.

Table 8. Power load for dynamic electricity price in case study.

\begin{tabular}{ccccc}
\hline \multirow{2}{*}{ Modeling Results } & \multicolumn{4}{c}{ Total Power (kW) } \\
\cline { 2 - 5 } & PSO [17] & TVAC-PSO [17] & BSO [18] & IRBSO \\
\hline Demand Response & 71,298 & 71,276 & 71,281 & 71,245 \\
Average Discharge & 71,403 & 71,382 & 71,393 & 71,182 \\
No Ice storage Tank & 71,618 & 71,609 & 71,613 & 71,549 \\
\hline
\end{tabular}

Table 9. Power load and dynamic electricity price for case results.

\begin{tabular}{ccccccc}
\hline IRBSO & $\begin{array}{c}\text { Modeling } \\
\text { Results }\end{array}$ & $\begin{array}{c}\text { Max. Load of } \\
\text { Peak (kW) }\end{array}$ & $\begin{array}{c}\text { Average Load } \\
\text { of Peak (kW) }\end{array}$ & $\begin{array}{c}\text { Max. Load of } \\
\text { Partial-Peak (kW) }\end{array}$ & $\begin{array}{c}\text { Min. Off-Peak } \\
\text { load (kW) }\end{array}$ & $\begin{array}{c}\text { Load Range } \\
*(\mathbf{k W})\end{array}$ \\
\hline \multirow{2}{*}{ Summer } & $\begin{array}{c}\text { Demand } \\
\text { Response }\end{array}$ & 3117.93 & 2809.27 & 3449.79 & 2668.20 & 449.73 \\
\cline { 2 - 7 } & $\begin{array}{c}\text { Average } \\
\text { Discharge }\end{array}$ & 3273.08 & 3133.38 & 3185.26 & 2671.36 & 601.72 \\
\cline { 2 - 7 } & $\begin{array}{c}\text { No Ice } \\
\text { Storage Tank }\end{array}$ & 3572.16 & 3434.18 & 3484.64 & 2290.03 & 1282.13 \\
\hline
\end{tabular}

${ }^{*}$ Load Range $=($ Max. Peak load $)-($ Min. Off-peak load $)$.

Table 9 shows the load range of the demand response to be $449.73 \mathrm{~kW}$ less than the average discharge of $601.72 \mathrm{~kW}$, and $1282.13 \mathrm{~kW}$ with no ice storage tank in the summer. As Tables 7 and 9 and the Figure 9 show, the average peak load of demand response average was $2809.27 \mathrm{~kW}$ less than the average discharge of $324.11 \mathrm{~kW}$, and that with no ice storage tank as $624.91 \mathrm{~kW}$. The system's maximum partial-peak load for the demand response was higher than the average discharge, but less than with no ice storage tank. There was a clear load shifting of the demand response in summer, as shown in Figure 9. 


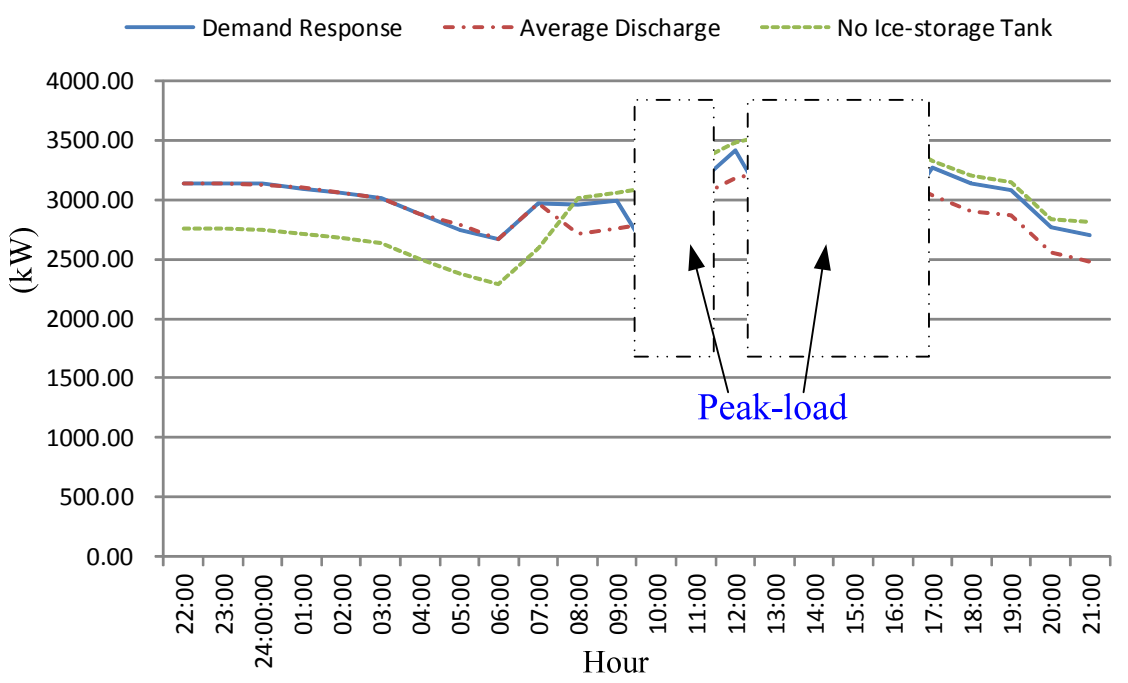

Figure 9. Simulation of dynamic electricity price.

\section{Conclusions}

This paper has presented the IRBSO algorithm to solve the ice storage air-conditioning system simulation and dynamic electricity price for the demand response problem. The IRBSO improved moving patterns and repulsion techniques for the diversity of solutions. In the test cases, the operating coefficients and cooling capacity of the chillers and ice storage tank were measured, and LSM was used to construct the curve model of the power consumption and cooling load. Based on the dynamic electricity price and all technical constraints, the dispatch model of the ice storage air-conditioning system was formulated by considering the ice storage discharging scheduling of demand response. This method could also improve the operating efficiency of ice storage and air-conditioning equipment. The planning of the charge and discharge processes of the ice storage tank for demand response study enhanced the operating efficiency of the chillers. This paper also provide greater energy efficiency in dispatching chillers and ice storage, thus reducing a user's electricity bill. The actual cases were used to verify the effectiveness of the proposed method.

Acknowledgments: This research work was supported in part by the research grants of Chang Gung Memorial Hospital under grant numbers CORPG8C1161-2 and CORPG8E0141-2. The funders had no role in study design, data collection and analysis, decision to publish, or preparation of the manuscript.

Author Contributions: Chi-Chun Lo designed the algorithm and handed the project, Bor-Shyh Lin prepared the manuscript as the corresponding author. Shang-Ho Tsai managed to obtain the data from fields and performed the experiments and conducted simulations.

Conflicts of Interest: The authors declare no conflict of interest.

\section{References}

1. Chua, K.J.; Chou, S.K.; Yang, W.M.; Yan, J. Achieving better energy-efficient air conditioning-A review of technologies and strategies. Appl. Energy 2013, 104, 87-104. [CrossRef]

2. Yan, C.; Xue, X.; Wang, S.; Cui, B. A novel air-conditioning system for proactive power demand response to smart grid. Energy Convers. Manag. 2015, 102, 239-246. [CrossRef]

3. Sanaye, S.; Shirazi, A. Thermo-economic optimization of an ice thermal energy storage system for air-conditioning applications. Energy Build. 2013, 60, 100-109. [CrossRef]

4. The Taiwan Power Company (TPC). Time-of-Use Rate for Cogenerator Plants; The Electricity Rate Structure for Taipower Company: Taipei, Taiwan, 2014.

5. Chassin, D.P.; Stoustrup, J.; Agathoklis, P.; Djilali, N. A new thermostat for real-time price demand response: Cost comfort and energy impacts of discrete-time control without deadband. Appl. Energy 2015, 155, 816-825. [CrossRef] 
6. Braun, J.E.; Kleni, S.A.; Mitchell, J.W.; Beckman, W.A. Applications of optimal control to chilled water systems without storage. ASHRAE Trans. 1989, 95, 663-675.

7. Lee, W.S.; Chen, Y.T.; Wu, T.H. Optimization for ice-storage air-conditioning system using swarm algorithm. Appl. Energy 2009, 86, 1589-1595. [CrossRef]

8. Sehar, F.; Rahman, S.; Pipattanasomporn, M. Impacts of ice storage on electrical energy consumptions in office buildings. Energy Build. 2012, 51, 255-262. [CrossRef]

9. Sebzali, M.J.; Rubini, P.A. The impact of using chilled water storage systems on the performance of air cooled chillers in Kuwait. Energy Build. 2007, 39, 975-984. [CrossRef]

10. Sebzali, M.J.; Rubini, P.A. Analysis of ice cool thermal storage for a clinic building in Kuwait. Energy Convers. Manag. 2006, 47,3417-3434. [CrossRef]

11. Chan, A.L.S.; Chow, T.T.; Fong, S.K.F.; Lin, J.Z. Performance evaluation of district cooling plant with ice storage. Energy 2006, 31, 2750-2762. [CrossRef]

12. Vo, D.N.; Ongsakul, W. Economic dispatch with multiple fuel types by enhanced augmented Lagrange Hopfield network. Appl. Energy 2012, 91, 281-289. [CrossRef]

13. Alsumait, J.S.; Sykulski, J.K.; Al-Othman, A.K. A hybrid GA-PS-SQP method to solve power system valve-point economic dispatch problems. Appl. Energy 2010, 87, 1773-1781. [CrossRef]

14. Sinha, N.; Chakrabarti, R.; Chattopadhyay, P.K. Evolutionary programming techniques for economic load dispatch. IEEE Trans. Evolut. Comput. 2003, 7, 83-94. [CrossRef]

15. Jahanbani Ardakani, A.; Fattahi Ardakani, F.; Hosseinian, S.H. A novel approach for optimal chiller loading using particle swarm optimization. Energy Build. 2008, 40, 2177-2187. [CrossRef]

16. Lee, W.S.; Lin, L.C. Optimal chiller loading by particle swarm algorithm for reducing energy consumption. Appl. Therm. Eng. 2009, 29, 1730-1734. [CrossRef]

17. Wang, X.; Dennis, M.; Hou, L. Clathrate hydrate technology for cold storage in air conditioning systems. Renew. Sustain. Energy Rev. 2014, 36, 34-51. [CrossRef]

18. Chen, H.J.; Wang, W.P.; Chen, S.L. Optimization of an ice-storage air conditioning system using dynamic programming method. Appl. Therm. Eng. 2005, 25, 461-472. [CrossRef]

19. Behnam, M.I.; Abbas, R.; Mehdi, E. Time-varying acceleration coefficients IPSO for solving dynamic economic dispatch with non-smooth cost function. Energy Convers. Manag. 2012, 56, 175-183.

20. Ratnaweera, A.; Halgamuge, S.; Watson, H.C. Self-organizing hierarchical particle swarm optimizer with time-varying acceleration coefficients. IEEE Trans. Evolut. Comput. 2004, 8, 240-255. [CrossRef]

21. Niknam, T.; Golestaneh, F. Enhanced bee swarm optimization algorithm for dynamic economic dispatch. IEEE Syst. J. 2013, 7, 754-762. [CrossRef]

22. Taher, N.; Seyed, I.T.; Jamshid, A.; Sajad, T.; Majid, N. A modified honey bee mating optimization algorithm for multiobjective placement of renewable energy resources. Appl. Energy 2011, 88, 4817-4830. 